\title{
Study of Effectiveness and Usability of Multimedia Courseware Integrated with 3-Dimensional Model as a Teaching Aid
}

\author{
Syazwan Noordin, Wan Fatimah Wan Ahmad, Yew Kwang Hooi \\ Universiti Teknologi PETRONAS \\ Perak, Malaysia.
}

\begin{abstract}
Tools based on Information Communication Technology (ICT) face serious usability problem for effective implementation in education delivery. This paper presents the study of a multimedia courseware using 3-Dimensional (3D) model for teaching a mathematical topic on Lines and Planes in 3-Dimensions. A field study with experimental approach was carried out on randomly selected students whereby a group of students was exposed to conventional learning, whereas the other group was aided with $3 \mathrm{D}$ visualization software. We conclude that the latter group showed significant improvement in attention, response and recall of the content.
\end{abstract}

\section{Keywords}

3-Dimensions, effectiveness, multimedia courseware, usability evaluation

\section{INTRODUCTION}

Researchers and technologists are continuously inventing various applications and tools for classroom usage such as multimedia courseware, augmented reality and virtual reality, some of which are available in the market [1]. The intention of using the technology is not to replace the traditional ways of teaching and learning, but rather to provide an additional aided learning tool for some areas that require more attention, and those which have been identified as needing alternative methods, apart from the normal way of teaching. An early analysis was conducted at Sekolah Menengah Kebangsaan Benta, Pahang, whereby a questionnaire was distributed to 31 form four students. From the survey, 14 out of 31 students were identified as having problem in visualizing Lines and Planes in 3-Dimensions [2], which is the final topic in KBSM form four Mathematics syllabus. The topic covers the identification of a plane and its properties, identifying and calculating the angle between a line and a plane, as well as identifying and calculating the angle between two planes [3]. The early identified problem is that, most of the students are not able to visualize the exact point of intersection between two planes, or a line with a plane which is sometimes hidden and unclear in 2-Dimensions (2D) image representation. As the result, the students fail to solve the mathematical questions related to this topic. Hence, it is believed that a 3-Dimensional representation in a multimedia courseware based on the same 2-Dimensional figure could lead to a better visualization ability and understanding for the students. Figure 1 shows an example of examination format question for the topic Lines and Planes in 3-Dimensions.

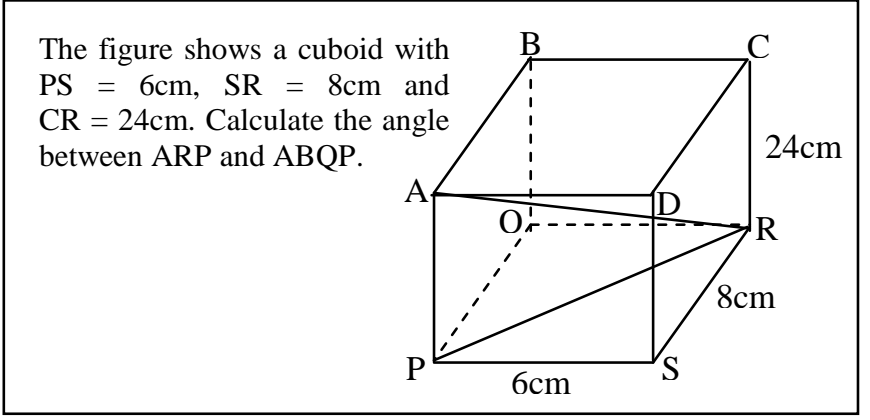

Figure 1 Example of Examination Question Format [3]

\section{LITERATURE REVIEW}

Multimedia courseware is one of the solutions in dealing with students' differences in learning styles and knowledge background since it integrates media elements that can engage human information retrieval methods which are visual, auditory, reading and kinaesthetic [2], [4], [5].

In reality, not all multimedia courseware in the market are suitable and usable for the users. Hence, the users must be sure that the courseware has been tested and verified by the developer in terms of its effectiveness for delivering the subject to the learners which is the main criteria of accepting a new courseware. Rogers et al. [6] define effectiveness as how good a product is at doing what it is supposed to do. Referring to the meaning of effectiveness, identifying the goal of a particular subject is the very first task in evaluating effectiveness. In the education context, the new multimedia courseware and aided learning tools are intended to boost the students' understanding as well as their performance in particular subject or topic. The effectiveness of a multimedia courseware can be determined by these two groups of people, namely the users (students) and the experts (teachers), which can be done quantitatively and qualitatively [7], [8]. In general, a courseware is considered effective when it can produce a good result and a positive impact to the students [8]. The effectiveness of a courseware can be evaluated by comparing the students test results before using the courseware i.e by conventional teaching method and after using the multimedia courseware [9]. Besides, in developing a courseware, usability testing is the process that must be considered after completing the application. As the goal of software evaluation is to ensure that a new application or product being produced is usable and pleasing to the users, the usability evaluation is specifically designed to assess the consistency of the interface and the interaction of a system with the user [6]. Practically, usability evaluation is done through "subjective user experiences with a self-evaluation questionnaire" comprising six assessment criteria which are effectiveness, efficiency, safety, utility, learnability and memorability [6],[10].

Reflecting on the earlier analysis, the students' problem is actually related to human spatial ability [2]. Human mental ability to see hidden or unclear information can be called as visualization ability, while spatial visualization is specifically related to mental intelligence for understanding about space, shapes and correlated information which are not clearly specified [11], [12]. The elaboration on spatial visualization is actually the main issue faced by the form four students in mathematics subject, specifically in the Lines and Planes in 3-Dimensions topic [2]. The identified problem must be seriously taken into consideration since it will directly affect the problem solving ability, and the students' performance in mathematics [13]. Hence, the potential and suggested solution for 
this problem is to use a 3-Dimensional model which can provide clearer information about a figure or diagram because it reflects the reality of that object which can be seen from three different perspectives [14]. The idea is also supported by other researches where a 3D model has been found to improve the visual interaction and ability to understand complicated figures or drawings as it combines various entity to give more precise and overall perspective of the object [15], [16].

The topic on Lines and Planes in 3-Dimensions is generally related to the study about shape and space, which is an important component in the KBSM mathematics curriculum [17]. Knowledge and skills in shapes or geometry will be very useful to be utilized in students' daily life [17]. This topic and the syllabus in general, are parallel with the van Hiele geometric thinking model in terms of the learning outcomes which has contributed towards improving students' visual skills and their understanding in geometry [17], [18]. The van Hiele theory states that there are five levels in geometric thinking which are Visualization (level 1), Analysis (level 2), Ordering (level 3), Deduction (level 4) and Rigor (level 5) [18]. In this study, the use of 3D model and the multimedia courseware aims to support the students' geometric thinking of level 1 (visualization) besides providing a learning aid for this topic. The students' ability to master the first level is very important in order for them to progress to the higher level of geometric understanding [19]. The expected learners' understanding for level 1 (visualization) is when the students are able to recognize the shapes and some of its properties [19]. The developed prototype multimedia courseware with $3 \mathrm{D}$ models is expected to provide the learners with the appropriate instruction and comprehensive information to facilitate visualization. Among the strategies and possible aided learning modules are listed in Table 1 [3], [19]:

Table 1 Learning Activities and Modules for Visualization

\begin{tabular}{|c|c|}
\hline Suggested Learning Activities & $\begin{array}{c}\text { Possible Aided Learning } \\
\text { Supports (Module) }\end{array}$ \\
\hline
\end{tabular}

\begin{tabular}{|c|c|}
\hline $\begin{array}{l}\text { Identifying and describing } \\
\text { shapes }\end{array}$ & Identifying Planes Module \\
\hline $\begin{array}{l}\text { Drawing and constructing } \\
\text { shapes }\end{array}$ & Sketching a 3D Shape Module \\
\hline $\begin{array}{l}\text { Seeing different orientations of } \\
\text { a shape to distinguish the } \\
\text { characteristics of a shape and } \\
\text { its properties }\end{array}$ & $\begin{array}{l}\begin{array}{l}\text { Freely } \\
\text { Module }\end{array} \\
\text { Rotated }\end{array}$ \\
\hline
\end{tabular}

\section{METHODOLOGY}

The main objective of this research is to identify the effectiveness and the usability aspect in the multimedia courseware for Lines and Planes in 3-Dimensions integrated with 3D models. The ADDIE model has been adopted as the flow guidelines for the whole courseware development process. Each phase of the courseware development starting from Analysis, Design, Development, Implementation and Evaluation has its own contribution towards the main objective of this research. The five development phases are summarized in Figure 2 below.

The analysis phase is the first and the most crucial phase in this project since it will uncover the problems of the subject under study. Both qualitative and quantitative data gathering methods namely interview and survey are used to dig out the problem regarding Lines and Planes in 3-Dimensions. The interview conducted at SMK Benta indicated that about $50 \%$ of the form four student have visualization problem [2]. The interview with one mathematics teacher from the same school also revealed that the students face difficulties in learning geometry due to their inability to visualize in $3 \mathrm{D}$. In addition to the interview, literature review on related studies has also been carried out to identify their focus area and to acquire ideas for the solution to the identified problem. Based on the interview results and literature review, the problem statements, objectives and scopes of the research were specified.

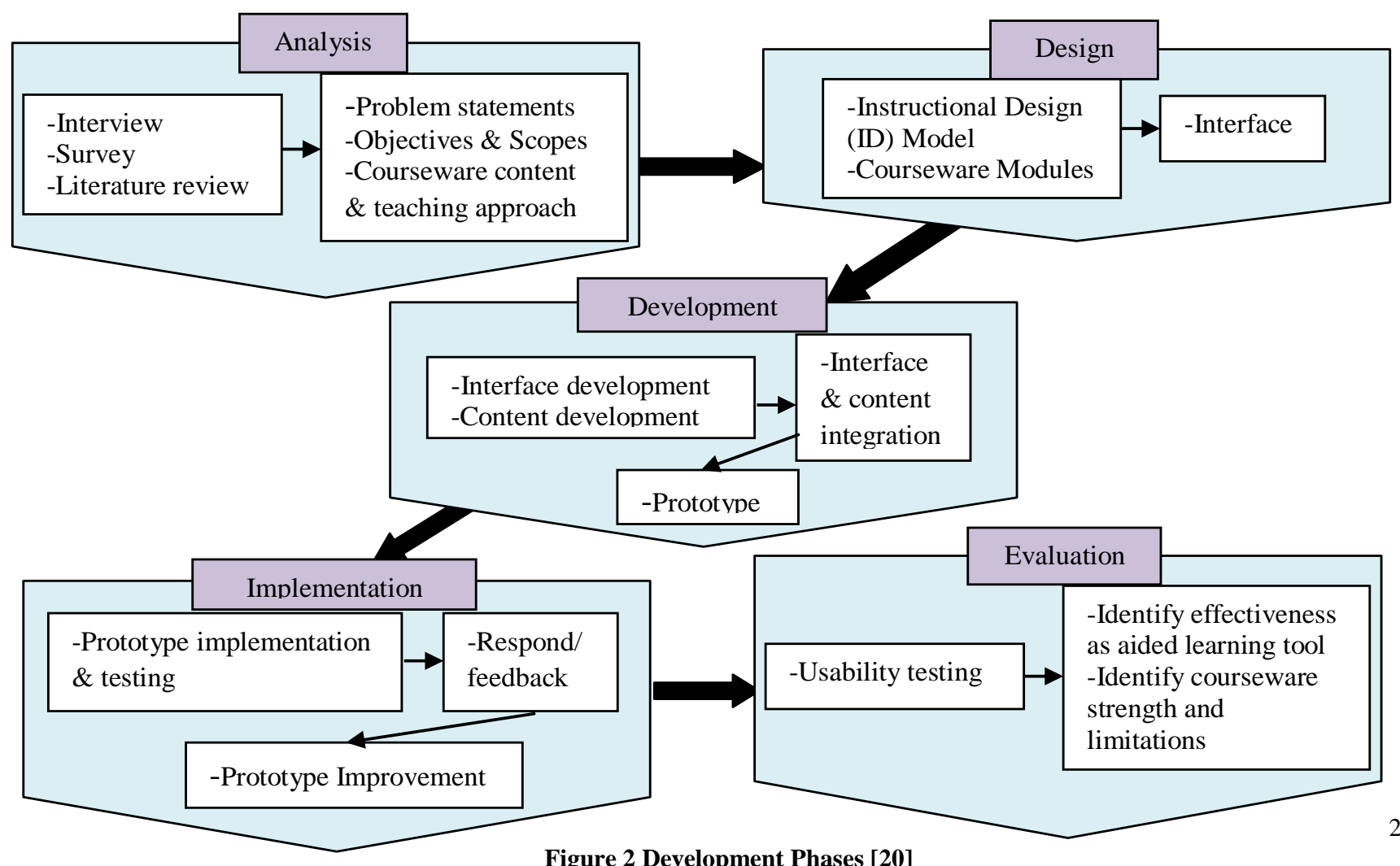

Figure 2 Development Phases [20] 


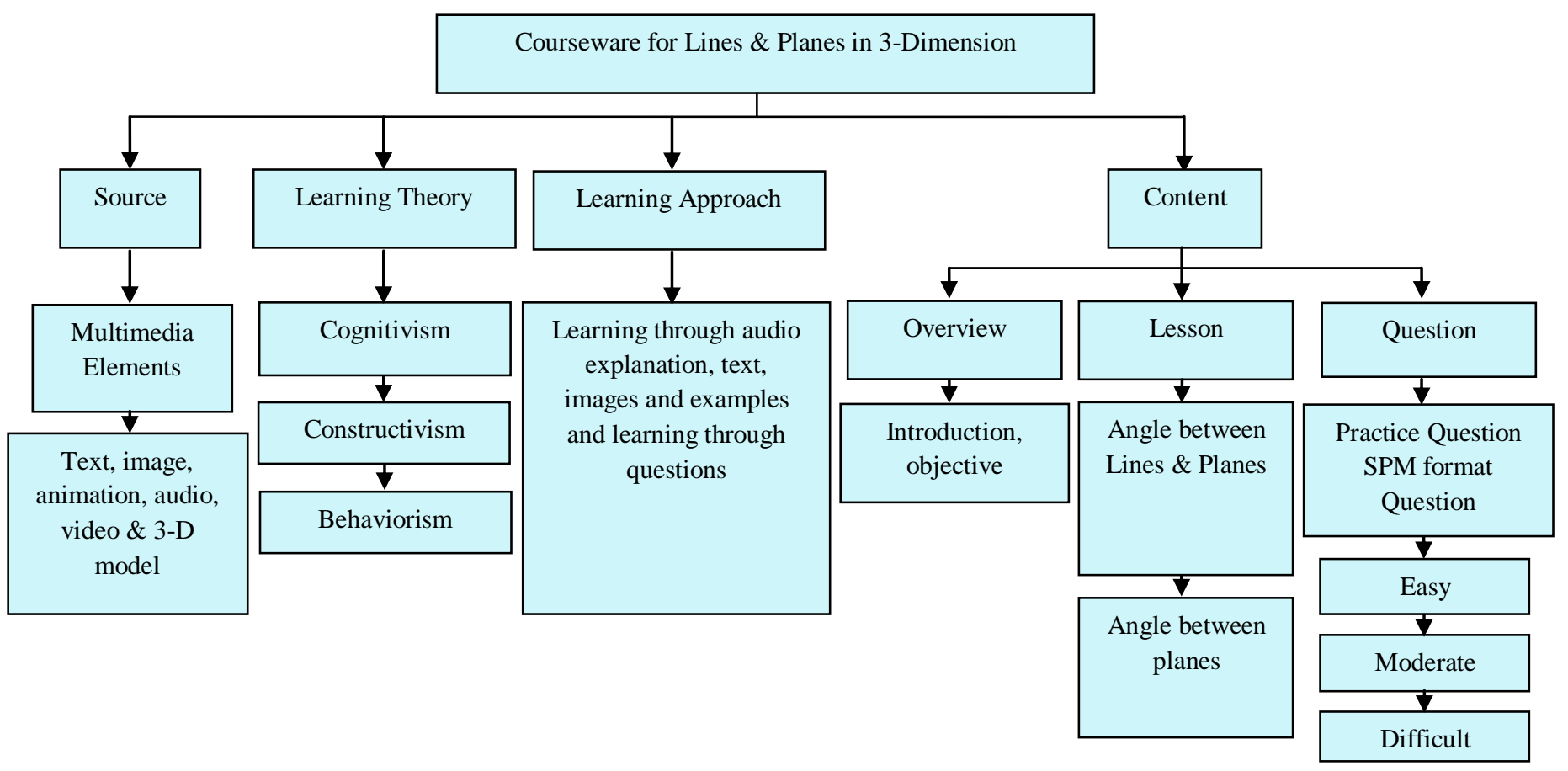

Figure 3 ID Model of Multimedia Courseware for Lines \& Planes in 3-Dimensions [20]

In the design phase, the Instructional Design (ID) Model for this research is identified based on the related design and learning theories in order to achieve the identified research and students' learning objectives. The ID Model for Lines and Planes in 3Dimensions courseware lists out media elements such as text, image, animation, video and 3-D model to be used in the application. The usage of 3-D model and mixture of instructional media will support the cognitivism learning theories in terms of visualization. The courseware contents are divided into 3 main sections namely: Overview, Lesson and Question. In Question section, the users or students will need to answer questions based on the topic learned that covers practice and SPM format questions. It is believed that the Question section will be able to support students in terms of constructivism learning theory because the students can develop their understanding based on self-directed activity. The ID Model for this courseware is depicted in Figure 3 below. 
The Courseware Modules as shown in Figure 4 is outlined based on the ID model and the KBSM mathematics syllabus for Lines and
The module is divided into three main categories which are Overview, Lesson and Questions which will be the main sections in

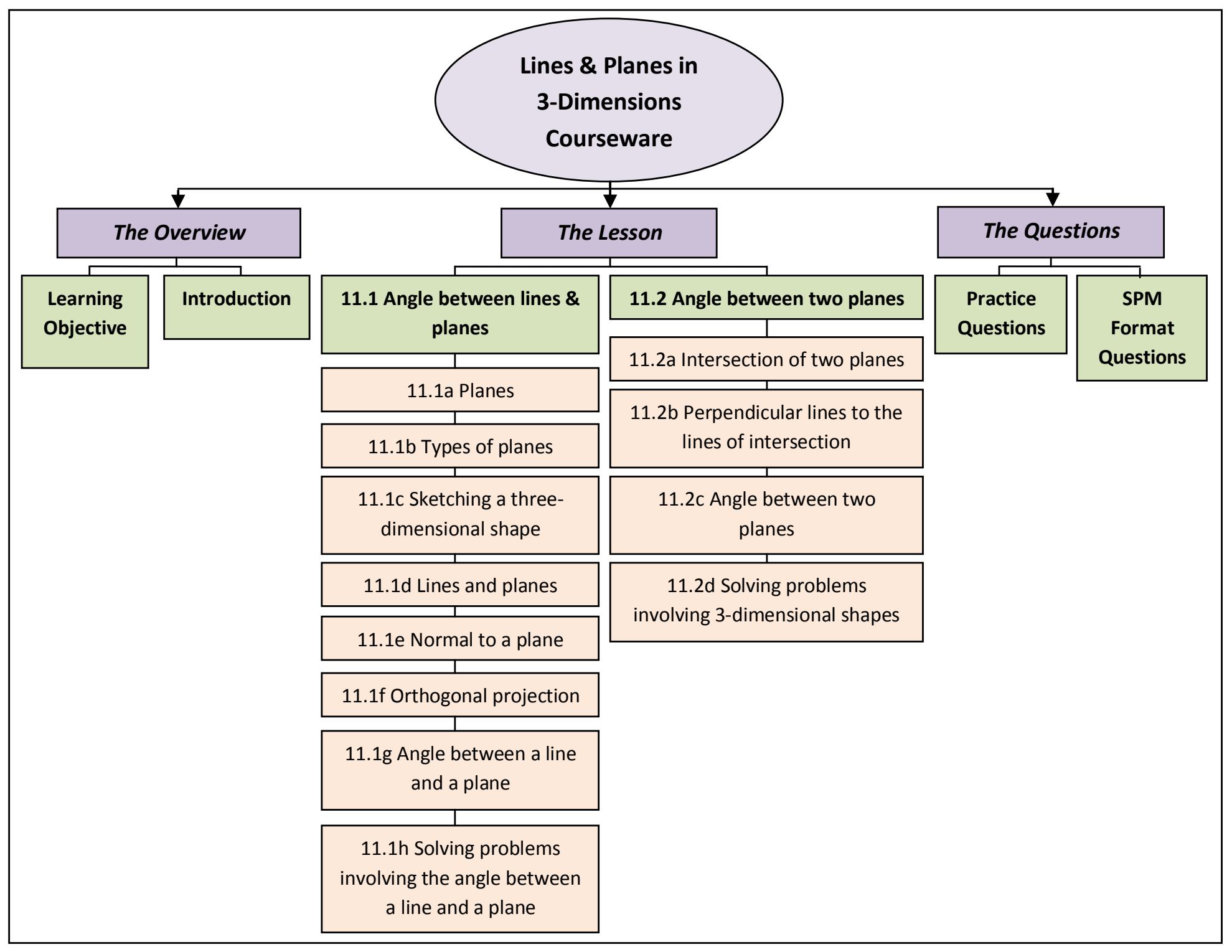

\section{Figure 4 Courseware Modules}

Planes in 3-Dimensions topic.

During the development phase, all the identified theories and design from the previous stage were referred for developing the working prototype. The early step before commencing the development process is to identify the required tools. In this project, the development tools being chosen are Macromedia Director MX, 3D Studio Max 7, and Adobe Photoshop CS2 which plays different roles for the development process. Macromedia Director MX is used as the multimedia authoring software whereby it will combines all the media elements in one screen. Since Macromedia Director is used as the multimedia authoring software, the most suitable 3-Dimensional authoring software is 3D Studio Max. Technically, the reason for using Macromedia Director with 3D Studio Max 7 is because it can the Lines and Planes in 3-Dimensions multimedia courseware.

render the developed 3-D model into Director's readable file format named '.W3D'. Adobe Photoshop CS2 is used as the picture editing software and tool for creating the icon of courseware interface. Apart from the technical tools, the development process of 'The Lesson' module highly relies on the Form Four Mathematics text book as the main source of content. Cross reference was also made by referring to several reference books available in the market. This is to make sure that the multimedia courseware prototype is rich in contents and informative for the students. 

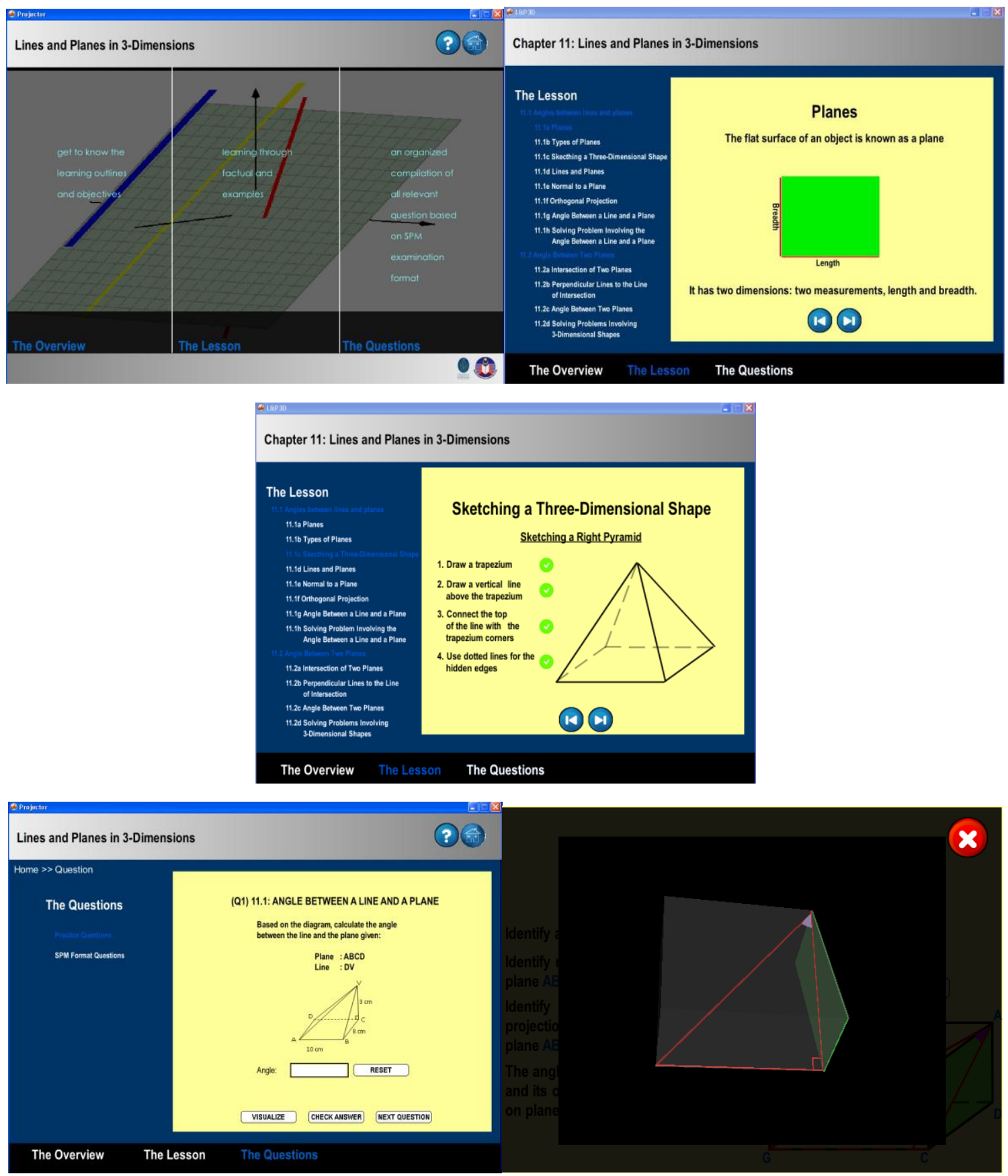

Some interfaces of the Lines and Planes in 3-Dimensions courseware are depicted in Figure 5.

Figure 5 Interfaces of the Courseware

Figure 5 shows some interfaces of the multimedia courseware for Lines and Planes in 3-Dimensions. The top left image is the main screen of the courseware that links to The Introduction, The Lesson and The Questions sections while the remaining images are the courseware modules screens. The modules are developed based on the ID Model, and the Courseware Module which are previously identified. The bottom right image shows a 3D model which can be rotated for aiding the process of learning geometry in general, or specifically in lines and planes. 
The implementation and evaluation phase are the most crucial in this project since it determines and evaluates the final findings based on the early identified objectives. In the implementation and evaluation phase, several methods or techniques have been used as illustrated in Figure 6 [21].

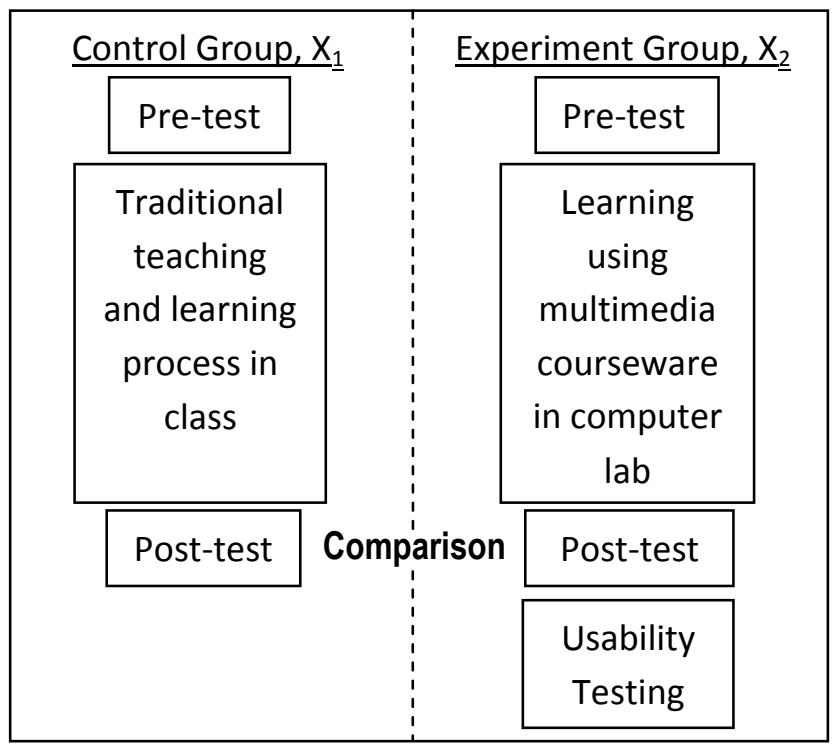

Figure 6 Courseware Effectiveness and Usability Testing Framework

The above framework illustrates the methods being implemented in this study. The process to identify the performance of the tested multimedia courseware is done based on quasi-experimental design. In this experiment, two schools namely Sekolah Menengah Kebangsaan Benta and Sekolah Menengah Kebangsaan Panglima Garang Abdul Samad were chosen. The students of Sekolah Menengah Kebangsaan Benta were assigned as the Experimental Group $\left(\mathrm{X}_{2}\right)$ while students from the other school as the Control Group $\left(X_{1}\right)$. Each group is comprised of 30 students. All students were required to answer pre-test questions before starting the lesson. After that, the $X_{1}$ students were taught by their Mathematics teacher in the traditional way, while the $\mathrm{X}_{2}$ students used the multimedia courseware for the lesson. After completing 3 hours and 20 minutes of the lesson (time allocated for both groups to cover the topic), the students were given the post-test questions based on the topic Lines and Planes in 3-Dimensions topic. The $\mathrm{X}_{2}$ students were required to attempt additional questionnaires on usability of the courseware. All data collected from the evaluation and tests were then compiled and analyzed using SPSS software. The post-test results for both groups were compared using t-test for hypothesis testing. A significant differecet found in the post-test results between the two groups will indicate the effectiveness of the 3D model and indirectly either accepts or rejects the early identified hypothesis. In perceiving the usability result of the multimedia courseware, the questionnaire was constructed based on these usability criteria which are effectiveness, efficiency, utility and learnability [6], [22], [23], [24]. The overall scores for both efficiency and usability of $\mathrm{X}_{2}$ group might not be accurate since there was one limitation that had occurred during the testing. The problem was that all desktops in the computer lab were not equipped with speakers or other audio devices. As the result, voice instructions or sounds could not be heard by the students while using the courseware.

\section{THE RESULTS AND DISCUSSIONS}

\subsection{Effectiveness Evaluation}

The quantitative data collected through the pre-test, post-test as well as usability questionnaires were statistically analyzed. The pre-test data were used to obtain the baseline performance of the students before learning the topic, while post-test data were used to indicate which methods is more effective for the students. Each group consists of 30 form four students or equivalent to $n=30$.

\subsubsection{Pre-test scores between the two groups}

Hypothesis $1\left(\mathrm{H}_{0} 1\right)$ - There is no significant difference in pre-test scores between the Control $\left(X_{1}\right)$ and the Experimental $\left(X_{2}\right)$ Groups

Table 2 Pre-Test Analysis

\begin{tabular}{|c|c|c|c|}
\hline Variable & Mean & SD & Sig. (2 tailed) \\
\hline Pre-test $\mathrm{X}_{1}$ & 1.3000 & 1.11880 & 0.58 \\
\hline Pre-test $\mathrm{X}_{2}$ & 1.2333 & 1.00630 & 0.58 \\
\hline
\end{tabular}

In general, the pre-test mark indicates that students from both groups are at the same level of knowledge whereby the mean score difference between $X_{1}$ and $X_{2}$ is just 0.0667 . The value of $p$ is 0.58 which is greater than $\alpha=0.05$. This indicates that there is no difference in the mean scores of pre-test for both groups, and the null hypothesis for Hypothesis $1\left(\mathrm{H}_{0} 1\right)$ is therefore accepted. Since both groups of students are at about the same level, this study is expecting that the sample selection has been accurately done and, will produce an accurate result.

\subsubsection{Post-test scores between the two groups}

Hypothesis $2\left(\mathrm{H}_{0} 2\right)$ - There is no significant difference in post-test scores between the Control $\left(X_{1}\right)$ and the Experimental $\left(X_{2}\right)$ Groups

Table 3 Post-Test Analysis

\begin{tabular}{|c|c|c|c|}
\hline Variable & Mean & SD & Sig. (2 tailed) \\
\hline Post-test $\mathrm{X}_{1}$ & 6.8000 & 1.91905 & 0.00 \\
\hline Post-test $\mathrm{X}_{2}$ & 8.8333 & 1.23409 & 0.00 \\
\hline
\end{tabular}

The above table shows the post-test results of this study. $\mathrm{X}_{1}$ group of students scored comparatively lower as compared to the $\mathrm{X}_{2}$ students result in the post-test with the mean score of 6.8000 and 8.8333 , respectively. The different in performance between both groups are statistically proven as the significant ( 2 tailed) value of $\mathrm{p}=0.00$ which is lesser than $\alpha=0.05$. Hence, the null hypothesis $\mathrm{H}_{0} 2$ is rejected which indirectly indicates that there is a significant difference of students' performance in post-test between $X_{1}$ and $X_{2}$ groups. Based on that statistical finding, it can be concluded that there are some improvements in average students mark after using the multimedia courseware which indirectly supports the early assumption of multimedia courseware with 3-Dimensional model as an effective tool aid in learning Lines and Planes in 3-Dimensions. 


\subsubsection{Increment scores between the two groups}

Hypothesis $3\left(\mathrm{H}_{0} 3\right)$ - There is no significant difference in student's increment scores between the Control $\left(X_{1}\right)$ and the Experimental $\left(X_{2}\right)$ Groups

Table 4 Increment between pre-test and post-test

\begin{tabular}{|c|c|c|c|}
\hline Variable & Mean & SD & Sig. (2 tailed) \\
\hline Increment $\mathrm{X}_{1}$ & 5.5000 & 2.08029 & 0.00 \\
\hline Increment $\mathrm{X}_{2}$ & 7.6000 & 0.89443 & 0.00 \\
\hline
\end{tabular}

The mean score of the post-test for the control group $\left(\mathrm{X}_{1}\right)$ is 5.5000 while the mean score for the experimental group $\left(\mathrm{X}_{2}\right)$ is 7.6000. The significant ( 2 tailed) value, $p=0.02$ is less than $\alpha=0.05$ which could indicate that the students in the experimental group achieved significantly higher scores after using the courseware in learning the Lines and Planes in 3-Dimension topic. This implies that the $\mathrm{H}_{0} 3$ is rejected as there is a significant difference in the increment between the two groups. The result shows the positive impact of learning through multimedia courseware which can be considered as effective.

\subsection{Usability Evaluation}

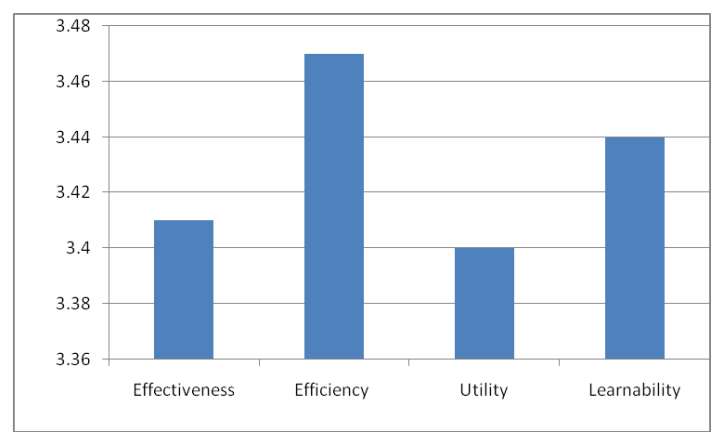

Figure 7 Usability Evaluation

The usability evaluation data were also compiled and analyzed to perceive the users' opinion about the courseware. There are 4 criteria of usability that were evaluated which are effectiveness, efficiency, utility and learnability as shown in Figure 7. The mean score for all areas being evaluated is 3.43 which signify that the courseware is above the average score, and well accepted by the users. The lowest score for this courseware is on the utility criteria while the highest score is on the efficiency of the courseware. The scores for effectiveness and efficiency show the positive impact of the 3D model, and the multimedia courseware on the students' performance. Also, based on users' feedback, 12 out of 30 students thought that 3Dimensions model is the most special feature in this multimedia courseware. The positive response given by the users on effectiveness usability criteria and 3D model indirectly indicates the potential of this courseware for motivating students to learn this topic. This also signifies the positive impact of this courseware for the students, whereby it is one of the criteria for an effective aided learning tool [8].

\section{CONCLUSION}

The paper has discussed the visualization problems faced by a group of form four students. The problem is that, the students cannot visualize the model or figure in Lines and Planes in 3-Dimensions. The usage of multimedia courseware integrated with 3D model is believed to be one of the solutions for the identified problem. The multimedia courseware with 3D model for Lines and Planes in 3Dimensions has been developed by adopting the ADDIE model as the main guideline for the entire development process. A quasi experimental design was implemented to evaluate the effectiveness and usability of the multimedia courseware. The result of the posttest has shown that students who used the multimedia courseware scored significantly higher than the students who learned the topic by the conventional teaching method. The result also indirectly reflects the effectiveness of the 3-D model for visualization and for understanding geometry because the group of students who used the courseware were able to identify the angle, and correctly answered the questions in the post-test which required them to understand the 2-D diagram in that question. In addition, result from the usability testing on the multimedia courseware also indicate positive acceptance from the students, however, there are still rooms for improvement before gaining maximum acceptance from the students. The paper concludes that a multimedia courseware integrated with $3 \mathrm{D}$ model is an effective and usable learning tool for teaching and learning Lines and Planes in 3-Dimension because it can positively contribute towards students understanding of the topic, thus, improving their performance and motivation.

\section{REFERENCES}

[1] Shawn Strong and Roger Smith. 2001. Spatial Visualization: Fundamentals and Trends in Engineering Graphics. Journal of Industrial Technology, Volume 18, Number 1. pp. 1-6

[2] Syazwan Noordin, Wan Fatimah Wan Ahmad and Yew Kwang Hooi. 2010. Survey on Visualization: Lines and Planes in 3Dimensions. 4th International Symposium on Information Technology, Proceeding Volume 1. pp. 473-476

[3] Lim Swee Hock, Chong Geok Chuan, Koo Seng Her, Samadi Hashim and Pumadevi Subramaniam. 2005. Mathematics Form Four, Integrated Curriculum for Secondary Schools, Darul Fikir, ISBN 978-983-131-249-0

[4] Understanding your Learning Style. 2003. University of Southampton.

Available: www.studyskills.soton.ac.uk/studyguides/Learning\%20Styles.d oc

[5] Syahrul Nizam Junaini and Jonathan Sidi. 2006. Enteramath: Interactive Online Mathematics Teaching and Learning through Animations. Proceeding of the International Conference on Distance, Collaborative and eLearning (DCEL 2005) 45, Kuala Lumpur

[6] Yvonne Rogers, Helen Sharp and Jenny Preece. 2007. Interaction Design: Beyond Human-Computer Interaction (2nd Edition). John Wiley \& Sons, Ltd ISBN 978-0-470-01866-8

[7] Behrouz H. Far, Vani Mudigonda and Abdel-Halim Elamy. 2009. A General Purpose Software Evaluation System. Informatica 33. pp. 261-270 
[8] Servet Bayram and Albert P. Nous. 2004. Evolution of Educational Software Evaluation: Instructional Software Assessment. The Turkish Online Journal of Educational Technology - TOJET April 2004 volume 3 Issue 2 Article 4. ISSN: 1303-6521. pp.21-27

[9] Sekaran U. 2000. Research Methods for Business: A SkillBuilding Approach. John Wiley. U.S. ISBN 0-471-33166-X

[10] Nokelainen, P. 2006. An Empirical Assessment of Pedagogical Usability Criteria For Digital Learning Material With Elementary School Students. Educational Technology \& Society, 9 (2). pp. 178-197

[11] Wikipedia (Last Modified on 21 October 2010). Spatial visualization ability. Available: http://en.wikipedia.org/wiki/Spatial_visualization_ability

[12] Jianping Yue. 2008. Spatial Visualization by Realistic 3D Views. Engineering Design Graphics Journal, Volume 72 Number 1. pp. 28-38

[13] Bülent GÜVEN and Temel KOSA. 2008. The Effect of Dynamic Geometry Software on Student Mathematics Teachers' Spatial Visualization Skills. The Turkish Online Journal of Educational Technology - TOJET, volume 7 Issue 4 Article 11. ISSN: 1303-6521, pp. 100-107

[14] The Benefits of 3D Modeling and Animation. Available: http://www.accenttech.com/illustration_services/3D_whitepaper _brief2.pdf

[15] Wikipedia (Last Modified on 29 October 2010). 3D Modeling. Available: http://en.wikipedia.org/wiki/3D_modeling

[16] Sultana Nasrin Nury, Xuan Zhu, Ian Cartwright and Laurent Ailleres. 2009. A 3-Dimensional Visualization - Decision Support Tool for Groundwater-Surface Water Connectivity Assessment. Proceedings of the Surveying \& Spatial Sciences Institute Biennial International Conference, Adelaide, Surveying \& Spatial Sciences Institute. ISBN: 978-0-9581366-8-6. pp. 1083-1094
[17] Curriculum Development Centre. 2004. Integrated Curriculum for Secondary Schools: Mathematics Syllabus, Ministry of Education Malaysia

[18] Erdogan Halat. 2006. Sex-Related Differences in the Acquisition of the Van Hiele Levels and Motivation In Learning Geometry. Asia Pacific Education Review, Vol. 7, No. 2. pp. 173-183

[19] Beatrice Moore Luchin. 2006. Geometry, Patterns and Process: Making the TAKS Connection. 2006 NUMBERS Mathematics Professional Development Available:

http://staff.beaumont.k12.tx.us/babel/Documents/geometrypatter nsprocess.doc

[20] Syazwan Noordin and Wan Fatimah Wan Ahmad. 2010. Implementation of Design and Learning Theories in Multimedia Courseware Development: Lines and Planes in 3-Dimensions. Proceeding of International Conference on User Science and Engineering. pp. 105-109

[21] Azizah Jaafar. 2008. Malaysian Smart School Courseware Usability study: The Effectiveness of Analytical Evaluation Technique Compared to Empirical Study. WSEAS Transactions on Information Science \& Applications, Issue 4, Volume 5. ISSN: 1790-0832. pp. 342-248

[22] Mazyrah Masri, Wan Fatimah Wan Ahmad, Shahrina Md Nordin. 2010. Learning English Literature through Multimedia. European Journal of Social Sciences - Volume 17, Number 2. pp. $238-253$

[23] Nor Azan Mat Zin, Halimah Badioze Zaman and Shahrul Azman Mohd Noah. 2009. Penilaian Perisian Kursus Adaptif Multimedia (A-Maths) Berasaskan Stail Pembelajaran. Jurnal Teknologi Maklumat \& Multimedia 5. pp. 61 -78

[24] James R. Lewis. 1993. IBM Computer Usability Satisfaction Questionnaires: Psychometric Evaluation and Instructions for Use. Technical Report 54.786. IBM Corporation. 